\title{
Three-dimensional Relationships between Condylar Volume and Dentoskeletal Characteristics in Class II Hyperdivergent Female Adults
}

Bingjie xie ( $\sim$ bingjiexie1111@163.com)

Sichuan University West China Hospital of Stomatology: Sichuan University West China College of Stomatology

Ye Tian

Sichuan University West China Hospital of Stomatology: Sichuan University West China College of Stomatology

Lingyi Huang

Sichuan University West China Hospital of Stomatology: Sichuan University West China College of Stomatology

\section{Anna Feng}

University of Texas Health Science Center at Houston School of Dentistry: The University of Texas Health Science Center at Houston School of Dentistry

\section{Xianglong Han}

Sichuan University West China Hospital of Stomatology: Sichuan University West China College of Stomatology

Juan Li

Sichuan University West China Hospital of Stomatology: Sichuan University West China College of Stomatology https://orcid.org/0000-0001-8320-2406

\section{Research Article}

Keywords: Three-dimensional analysis, Class II hyperdivergent, Temporomandibular disorders, Condylar morphology, Dentofacial characteristics

Posted Date: January 27th, 2022

DOI: https://doi.org/10.21203/rs.3.rs-1192633/v1

License: (1) This work is licensed under a Creative Commons Attribution 4.0 International License. Read Full License 


\section{Abstract}

Background: To determine the difference among various volume of condylar osseous patterns and the corresponding dentoskeletal characteristics in TMD high-risk groups.

Methods: Craniofacial spiral computed tomography data of 60 Class II hyperdivergent female adults were divided into normal, resorptive, flattened, and osteophyte groups based on condylar osseous forms. The condylar volume of each group was compared, and their correlations with dentoskeletal characteristics were assessed in three-dimensions.

Results: 1. The condylar volume of the normal group was significantly greater than that of the changed group. There were no significant differences among the changed subgroups. 2. The decrease in condylar volume was associated with a more retruded and clockwise rotated mandible with shorter rami. 3. The condylar volume was negatively correlated with overjet, the alveolar height of lower anterior teeth and posterior teeth, the sagittal inclinations of lower teeth, the buccal inclination and intermolar width of mandibular first molars, and the width between the corresponding alveolar crests.

Conclusion: Multiple three-dimensional dentoskeletal characteristics of Class II hyperdivergent female adults are correlated to condylar bony changes regardless of changing forms. These results could be helpful in indicating potential pathological changes of TMJ and making proper treatment plans for these patients.

\section{Background}

The morphology of the temporomandibular joint (TMJ) are associated with the dynamic balance of mandibular functions, and could affect the relationship between the maxilla and mandible in all dimensions. Being an important part of the TMJ, the condyle are of great importance on the long-term stability of orthodontic and orthognathic treatment and should be considered in treatment planning ${ }^{1-3}$.

The condylar morphology may be determined by different loading modes of various craniofacial morphologies ${ }^{4}$. Besides for physiological factors, several pathological conditions such as temporomandibular disorders (TMD) ${ }^{5}$, idiopathic condylar resorption ${ }^{6}$, and rheumatoid arthritis ${ }^{7}$ could influence the condylar volume and shape. These remodeling or degenerative changes of the condyle include erosion, resorption, flattening, sclerosis and osteophyte formation ${ }^{8}$. Therefore, the measurements of condylar morphology may be helpful in indicating risk factors for some pathologies.

Though there were some controversy ${ }^{9}$, condyle morphology was thought to associate with craniofacial and occlusal features $^{9-11}$. Moreover, the degenerative changes of the condyle may link to some dentofacial characteristics ${ }^{12}$. However, no studies have compared the particular differences among various bony change forms of the condyle, and the correlation between dentoskeletal characteristics and the forms of condylar osseous alteration have not been explored.

Traditional studies used lateral cephalograms to study sagittal/vertical dentofacial structures $8,12,13$, which rose the possibility of error caused by superimposition of neighboring structures. Additionally, little is known about the association between condyle features and transverse skeletal/occlusal conditions. Besides, although some studies attempted to assess condylar morphology using computerized tomography (CT), most of the measurements were conducted in $2 \mathrm{D}$ planes ${ }^{9,14,15}$. Hence it is imperative to use a three-dimensional approach to evaluate the relationship between condylar osseous changes and dentofacial modalities more accurately.

The aim of this retrospective study was to (1) compare the condylar volume among condyles with different morphological bony changes; (2) determine the interrelationship between condylar volume and dentofacial characteristics in three dimensions using CT images. In order to minimize bias, the subjects in this study were confined to skeletal class II hyperdivergent female adults. 


\section{Methods}

The sample consisted of 60 subjects who had received craniofacial spiral computed tomography scans in XWest China Hospital of Stomatology for any reason from June 2018 to April 2021s. Samples were selected based on the following inclusion criteria: (1)20-40-year-old female; (2)skeletal Class II, $\angle \mathrm{ANB} \otimes 5^{\circ}$; (3)hyperdivergent profile( $\angle \mathrm{SN}-\mathrm{MP} \llbracket 40^{\circ}, \angle \mathrm{FMA} \llbracket 32^{\circ}$, posterior/total facial height ratio $₫ 65 \%$ ); (4)no facial asymmetry (menton deviates from midsagittal plane less than $2 \mathrm{~mm}$ ); (5)no cleft lip or palate, craniofacial syndrome, trauma, orthodontic or surgery treatment history; (6)fully erupted permanent teeth; no malformed, ectopic erupted, or missing teeth; (7)no crowns, implants, brackets or cuspal restorations; (8)no apparent crowding (less than $5 \mathrm{~mm}$ per arch); (9)no cross bite; (10)if condylar bony changes exist, the changes should be seen in at least 2 consecutive slides of CT images and the cortical bone of the condylar surface should be continuous ${ }^{16}$. Class II division 2 was excluded.

Subjects were divided into normal and changed groups. The normal group had 15 subjects with no obvious bony changes or abnormal morphology on either side of the condyle. The changed groups were defined as samples with evident bilateral identical bony changes on the condyles. The changed group was then subdivided into: resorption, flattening, and osteophyte group (Fig 1). The resorption group had 15 subjects including partial bone loss other than surface flattening on condylar heads. The flattening group had 16 subjects who had a flat bony contour deviating from the normal convex forms of condyles. The osteophyte group had 14 subjects manifesting as marginal bony outgrowths on condyles ${ }^{8}$.

The CT equipment was Philips MX 16-slice and the images were obtained at $90 \mathrm{kV}, 40 \mathrm{~mA}$, and a voxel size of $0.49 \mathrm{~mm}$. The images were saved as digital imaging and communication in medicine (DICOM) files and reconstructed in Dolphin Software Program (Dolphin Imaging Software 11.7, Chatsworth, CA91311, USA). Reorientation of each scan was performed using the standardize head position ${ }^{16}$ (Fig 2).

Unilateral condyle was separated from the skull by Clipping and Sculpting in Dolphin. The following planes were used to define the borders of condyles: a plane tangent to Condylion (Co) point and parallel to the axial plane was used as the superior boundary; a plane tangent to the most inferior point of sigmoid notch and parallel to the axial plane served as the inferior boundary; a plane passing through the deepest point of sigmoid notch and perpendicular to the axial plane was determined as the anterior border; and a plane tangent to the most posterior point of condyle (Pcd) and perpendicular to the axial plane was characterized as the posterior border ${ }^{17}$ (Fig 3). Once the condyle was isolated, the condylar volume in each group could be measured by Dolphin.

Table 1 gives the landmarks, plans and measurements for analyses. Skeletal and dentoalveolar variables were measured in the CT images or converted images (Fig 4-8). Lateral cephalograms from the CT imaging based on the left and right half of the skull reconstructed respectively. Variables on the cephalometrics were measured separately on each half, and the average was calculated and recorded.

\section{Statistical analysis}

All statistical analyses were performed by SPSS software program (version 20.0; IBM, Armonk, NY). Measurements of this study were performed by two experienced orthodontists. After a two week interval, 20 subjects were randomly selected and remeasured for all variables. The intraclass correlation coefficient (ICC) was calculated to examine intraobserver reliability, while their first and last measurement was used to examine interobserver reliability. Means \pm standard deviations were used if the data exhibited normal distribution. Pairwise least significant difference tests were used to examine individual pairwise differences between the groups, and one-way ANOVA was used to measure differences among multiple groups. Pearson correlation and Spearman rank correlation analysis were used to determine the correlation between condyle volume and dentofacial characteristics. Linear regression analysis was later performed to establish the regression equation. A $P$ value less than 0.05 was considered to be statistically significant. 


\section{Results}

The ICC values ranged from 0.916 to 0.921 for intraobserver reliability and from 0.907 to 0.931 for interobserver reliability, indicating satisfactorily reproduction of these measurements. There was no significant difference between condyles on the left/right side within each group $(P>0.05)$ (Table 2$)$. Therefore the average volume of the left and right condyles was used for further analyses.

The condylar volume was significantly higher in the normal group than other three changed groups $(P<0.05)$. However, when compared pairwise, there was no significant difference among the three changed groups $(P>0.05)($ Table 3$)$. Hence we decided to focus on analyzing the interrelationship between condylar volume and dentofacial characteristics.

In the vertical plane, the condylar volume was positively correlated with Co-Go, S-Go, S-Go/N-Me and negatively correlated with $\angle \mathrm{SN}-\mathrm{OP}$, $\angle \mathrm{SN}-\mathrm{MP}, \angle \mathrm{FMA}, \angle \mathrm{PP}-\mathrm{MP}$, U6-PP, L6-MP, L1-MP $(\mathrm{P}<0.05)($ Table 4).

In the sagittal plane, the condylar volume was positively correlated with $\angle \mathrm{SNB}, \mathrm{Co}-\mathrm{Me}, \angle \mathrm{U} 1-\mathrm{L} 1$ and negatively correlated with $\angle A N B$; the sagittal inclination of lower posterior teeth; $\angle \mathrm{IMPA}$; and overjet $(\mathrm{P}<0.05)$, but no significant correlation with $\angle \mathrm{SNA}$, Go-Me, and $\angle \mathrm{U} 1-\mathrm{SN}$ (Table 5).

In the transverse plane, the condylar volume showed a weak positive correlation with the buccolingual alveolar crest width of maxillary first molar (U6-BLW) and a negative correlation with the angle between mandibular first molar and the sagittal plane ( $\angle \mathrm{L} 6 /$ Sagittal) on both sides, mandibular first molar arch width (L6-IM), and the mandibular transverse width at alveolar crests of first molars $(\mathrm{L6}-\mathrm{AC})(\mathrm{P}<0.05)$ (Table 6).

\section{Discussion}

Condylar morphology can be changed as a result of adaptive remodeling to functional or pathological stimulis even after growth has ceased ${ }^{18}$. Knowledge of the condyle is essential for correctly assessing the TMJ status and treatment planning. TMJ morphology and the position of the condylar head varies in diverse sagittal and vertical skeletal patterns ${ }^{11}$. Our research specifically evaluated the difference between the morphological bony changes of the condyle of Class II hyperdivergent female and their association with dentoskeletal characteristics.

Most studies evaluated condylar size in some specific plane ${ }^{19,20}$. By conducting 3D measurements, we found that the condylar volume of changed groups was significantly smaller in comparison to the normal group. Since function affects form ${ }^{18}$, larger condyle seemed to be more resistant to stimulations, while smaller condyle may provide unreliable support for stimulations and thus prone to pathological changes ${ }^{21}$. Flattening of the condyle may be the first adaptive alteration to degenerative changes of the $\mathrm{TMJ}^{22}$. Resorption of the head probably result in occlusal changes ${ }^{23}$. Osteophyte formation was considered to widen the condylar surface in an attempt to stabilize and improve the loading capacity ${ }^{24}$. Surprisingly, our study showed no significant difference among condylar volumes of the three groups. We speculate that condyle may diminish after adaptive alteration no matter what changing form is.

Our results indicated that condylar volumetric reduction was accompanied with shorter mandibular length, ramus height, posterior facial height, reduced posterior to anterior facial height ratio, but was not associated with anterior facial height, lower face height or mandibular length (Fig. 9A). Overall, the mandible displayed a clock-wise rotation with condylar volumetric reduction, but the maxilla relatively stayed the same. Ahn et al. found the a similar trend that posterior facial and ramus height were significantly different between those with or without degenerative diseases ${ }^{25}$. Nonetheless, Gidarakou et al. found a reduction on both SNA and SNB angle in TMJ degenerative patients ${ }^{26}$. The increase of the alveolar height of posterior teeth as well as the mandibular anterior teeth may result from compensational extrusion of the teeth after clockwise rotation of the mandible. 
We speculate that when mandible rotated clockwise, the component of occlusal force that made the lower posterior teeth tip mesially would be greater. But the upper posterior teeth were less impacted since they were more upright in the alveolar bone. The mesially tipped lower posterior compensated for the possible deterioration of the sagittal occlusal discrepancy. Meanwhile, lower incisors protruded in order to have occlusal contacts with upper incisors. But the compensation was insufficient for the increased overjet caused by the retrusive mandible. In addition, muscular activity should be taken into consideration. Tongue pressure on the lower incisors increased when the mandible retruded, while the labial-lingual muscle strength on the upper incisors were almost in balance. Thus in our study, condylar volume was positively correlated with $\angle \mathrm{U} 1-\mathrm{L} 1$ and negatively correlated with $\angle \mathrm{IMPA}$ and overjet, but not correlated with $\angle \mathrm{U} 1-\mathrm{SN}$ (Fig. 9B).

No previous study has established the interrelationship between condylar bony changes and dentoskeletal features in the transverse dimension. Our results implied that condylar volume had no correlation with transverse measurements of upper posterior teeth. We hypothesized that when mandible rotated clockwise, the retropositioned lower arch occluded with wider posterior upper arch. Thus the occlusal force on the lower molars was more buccally inclined. Meanwhile, forces of tongue muscle pressure on lower molars relatively increased. As a consequence, buccal inclination and arch width of the lower first molars increased (Fig. 9C). The basal bone inclination frequently aligned with the inclination of the mandibular molars ${ }^{27}$. Thus the width between the buccal alveolar crests in the lower first molar section also increased.

Our study established a comprehensive correlation between condylar volume and dentofacial deformities, which would be useful for indicating potential pathological changes of TMJ. However, the cause-and-effect relationship remains unclear. A homogeneous population may have racial, gender and skeletal differences affection on the results, this need to be clarified in future studies. Besides, it was not possible to take CT scans on more subjects to enlarge the sample size due to ethical reasons, so the results of this study would be better interpreted and supported by new studies.

\section{Conclusions}

1. Condylar bony changes showed a reduction in volume when compared to normal condyles regardless of changing forms.

2. Vertically, a decrease in condylar volume was associated with a decrease in rami, posterior facial height, posterior to anterior face height ratio, total mandibular length, and an increase of occlusal plane angle and mandibular plane angle, indicating the clockwise rotation of mandible. Meanwhile, the alveolar height of posterior teeth and mandibular anterior teeth increased along with the decrease in condylar volume.

3. Sagittally, a decrease in condylar volume was accompanied by a more retruded mandible, more mesially tipping mandibular posterior teeth, more labially inclined mandibular anterior teeth, and larger overjet.

4. Transversely, a decrease in condylar volume correlated with an increase in buccal inclination, arch width, and alveolar crests width of the mandibular first molars.

\section{Abbreviations}

TMD: Temporomandibular disorders

TMJ: Temporomandibular joint

CT: Computerized tomography

CO: Condylion

ICC: Intraclass correlation coefficient

\section{Declarations}




\section{Ethics approval and consent to participate}

This study was approved by the medical ethics committee of (IRB number: XWCHSIRB-ST-2018-130)West China Hospital of Stomatology, Sichuan University, Chengdu, China.

\section{Consent for publication}

Not applicable

\section{Availability of data and materials}

The datasets used and/or analysed during the current study are available from the corresponding author on reasonable request.

\section{Competing interests}

The authors declare that they have no competing interests

\section{Funding}

This work was supported by the Science and Technology of the People's Republic of China (Grant 2018FY10100003)

\section{Authors' contributions}

BX carried out the statistical analysis and drafted the manuscript. YT revised the manuscript and contributed to manuscript finalization. LH collected the data. AF assisted in data analysis. XH designed the study and collected the data. JL supervised the study, measurements and analysis. All authors read and approved the final manuscript.

\section{Acknowledgements}

Not applicable

\section{References}

1. Fan XC, Ma LS, Chen L, Singh D, Rausch-Fan X, Huang XF. Temporomandibular Joint Osseous Morphology of Class I and Class II Malocclusions in the Normal Skeletal Pattern: A Cone-Beam Computed Tomography Study. Diagnostics (Basel) Mar 18 2021;11(3)doi:10.3390/diagnostics11030541.

2. Noh KJ, Baik HS, Han SS, Jang W, Choi YJ. Differences in mandibular condyle and glenoid fossa morphology in relation to vertical and sagittal skeletal patterns: A cone-beam computed tomography study. Korean J Orthod Mar. 2021;25(2):126-34. doi:10.4041/kjod.2021.51.2.126. 51 ) .

3. Saccucci M, Polimeni A, Festa F, Tecco S. Do skeletal cephalometric characteristics correlate with condylar volume, surface and shape? A 3D analysis. Head Face Med May. 2012;15:8:15. doi:10.1186/1746-160x-8-15.

4. Saccucci M, D'Attilio M, Rodolfino D, Festa F, Polimeni A, Tecco S. Condylar volume and condylar area in class I, class II and class III young adult subjects. Head Face Med Dec. 2012;14:8:34. doi:10.1186/1746-160X-8-34. 
5. Paknahad M, Shahidi S, Akhlaghian M, Abolvardi M. Is Mandibular Fossa Morphology and Articular Eminence Inclination Associated with Temporomandibular Dysfunction? J Dent (Shiraz) Jun. 2016;17(2):134-41.

6. Exposto CR, Stoustrup P, Kristensen KD, Dalstra M, Pedersen TK. Condylar changes in patients with idiopathic condylar resorption: retrospective 2-year follow-up CBCT-based case-control study. Eur J Orthod Feb 9 2020;doi:10.1093/ejo/cjz099.

7. Youssef Mohamed MM, Dahaba MM, Farid MM, Ali Elsayed AM. Radiographic changes in TMJ in relation to serology and disease activity in RA patients. Dentomaxillofac Radio/ Jan. 2020;49(1):20190186. doi:10.1259/dmfr.20190186.

8. Alexiou K, Stamatakis $\mathrm{H}$, Tsiklakis K. Evaluation of the severity of temporomandibular joint osteoarthritic changes related to age using cone beam computed tomography. Dentomaxillofac Radio/ Mar. 2009;38(3):141-7. doi:10.1259/dmfr/59263880.

9. Rodrigues AF, Fraga MR, Vitral RW. Computed tomography evaluation of the temporomandibular joint in Class II Division 1 and Class III malocclusion patients: condylar symmetry and condyle-fossa relationship. Am J Orthod Dentofacial Orthop Aug. 2009;136(2):199-206. doi:10.1016/j.ajodo.2007.07.033.

10. Schiffman E, Ohrbach R, Truelove E, et al. Diagnostic Criteria for Temporomandibular Disorders (DC/TMD) for Clinical and Research Applications: recommendations of the International RDC/TMD Consortium Network* and Orofacial Pain Special Interest Groupt. J Oral Facial Pain Headache Winter. 2014;28(1):6-27. doi:10.11607/jop.1151.

11. Katsavrias EG. Morphology of the temporomandibular joint in subjects with Class II Division 2 malocclusions. Am J Orthod Dentofacial Orthop Apr. 2006;129(4):470-8. doi:10.1016/j.ajodo.2005.01.018.

12. Braz Oral Res. 2016;30doi:10.1590/1807-3107BOR-2016.vol30.0017.

13. Byun ES, Ahn SJ, Kim TW. Relationship between internal derangement of the temporomandibular joint and dentofacial morphology in women with anterior open bite. Am J Orthod Dentofacial Orthop Jul. 2005;128(1):87-95. doi:10.1016/j.ajodo.2004.01.028.

14. Wiese M, Hintze H, Svensson P, Wenzel A. Comparison of diagnostic accuracy of film and digital tomograms for assessment of morphological changes in the TMJ. Dentomaxillofac Radiol Jan. 2007;36(1):12-7. doi:10.1259/dmfr/78486936.

15. Sanders DA, Rigali PH, Neace WP, Uribe F, Nanda R. Skeletal and dental asymmetries in Class II subdivision malocclusions using cone-beam computed tomography. Am J Orthod Dentofacial Orthop. Nov 2010;138(5):542.e1-20; discussion 542-3. doi:10.1016/j.ajodo.2010.02.027.

16. Ahn J, Kim SJ, Lee JY, Chung CJ, Kim KH. Transverse dental compensation in relation to sagittal and transverse skeletal discrepancies in skeletal Class III patients. Am J Orthod Dentofacial Orthop Jan. 2017;151(1):148-56. doi:10.1016/j.ajodo.2016.06.031.

17. da Silva RJ, Valadares Souza CV, Souza GA, et al. Changes in condylar volume and joint spaces after orthognathic surgery. Int J Oral Maxillofac Surg Apr. 2018;47(4):511-7. doi:10.1016/j.ijom.2017.10.012.

18. Hiiemae K. Functional Aspects of Primate Jaw Morphology. Food Acquisition and Processing in Primates; 1984.

19. Park IY, Kim JH, Park YH. Three-dimensional cone-beam computed tomography based comparison of condylar position and morphology according to the vertical skeletal pattern. Korean J Orthod Mar. 2015;45(2):66-73. doi:10.4041/kjod.2015.45.2.66.

20. Kurita H, Koike T, Narikawa J, Nakatsuka A, Kobayashi H, Kurashina K. Relationship between alteration of horizontal size and bony morphological change in the mandibular condyle. Dentomaxillofac Radio/ Nov. 2003;32(6):355-8. doi:10.1259/dmfr/70038602.

21. Krisjane Z, Urtane I, Krumina G, Zepa K. Three-dimensional evaluation of TMJ parameters in Class II and Class III patients. Stomatologija. 2009;11(1):32-6.

22. Crusoé-Rebello IM, Campos PS, Rubira IR, Panella J, Mendes CM. Evaluation of the relation between the horizontal condylar angle and the internal derangement of the TMJ - a magnetic resonance imaging study. Pesqui Odontol Bras 
Apr-Jun. 2003;17(2):176-82. doi:10.1590/s1517-74912003000200015.

23. Hussain AM, Packota G, Major PW, Flores-Mir C. Role of different imaging modalities in assessment of temporomandibular joint erosions and osteophytes: a systematic review. Dentomaxillofac Radio/ Feb. 2008;37(2):6371. doi:10.1259/dmfr/16932758.

24. dos Anjos Pontual ML, Freire JS, Barbosa JM, Frazão MA, dos Anjos Pontual A. Evaluation of bone changes in the temporomandibular joint using cone beam CT. Dentomaxillofac Radiol Jan. 2012;41(1):24-9. doi:10.1259/dmfr/17815139.

25. Ahn SJ, Kim TW, Nahm DS. Cephalometric keys to internal derangement of temporomandibular joint in women with Class II malocclusions. Am J Orthod Dentofacial Orthop. Oct 2004;126(4):486-94; discussion 494-5. doi:10.1016/j.ajodo.2003.08.029.

26. Gidarakou IK, Tallents RH, Kyrkanides S, Stein S, Moss M. Comparison of skeletal and dental morphology in asymptomatic volunteers and symptomatic patients with bilateral degenerative joint disease. Angle Orthod Feb. 2003;73(1):71-8.

27. Alkhatib R, Chung CH. Buccolingual inclination of first molars in untreated adults: A CBCT study. Angle Orthod Jul. 2017;87(4):598-602. doi:10.2319/110116-786.1.

\section{Tables}

Table 1

Definition of points, measurement planes and measurements. 


\begin{tabular}{|c|c|}
\hline Landmarks & Definition \\
\hline $\mathrm{N}$ & Nasion \\
\hline S & Sella \\
\hline Or & Orbitale \\
\hline$P$ & Porion \\
\hline ANS & Anterior nasal spine \\
\hline PNS & Posterior nasal spine \\
\hline$A$ & Point A \\
\hline U1 & Incisal edge of maxillary incisor \\
\hline U1A & Apex of maxillary incisor \\
\hline L6A & Apex of mandibular first molar \\
\hline B & Point B \\
\hline Me & Menton \\
\hline Go & Gonion \\
\hline$J$ & Interjugular point \\
\hline$A G$ & Antegonial notch point \\
\hline $\begin{array}{l}\text { Measurement } \\
\text { planes }\end{array}$ & Definition \\
\hline SN & Sella nasal plane \\
\hline $\begin{array}{l}\text { FH. Frankfort } \\
\text { horizontal } \\
\text { plane }\end{array}$ & Plane passing through bilateral porions and the midpoint of bilateral orbitales \\
\hline $\begin{array}{l}\text { PP. Palatal } \\
\text { plane }\end{array}$ & Perpendicular to the sagittal plane, passing through ANS and PNS \\
\hline $\begin{array}{l}\text { OP. Occlusal } \\
\text { plane }\end{array}$ & Functional occlusal plane, along the maximum intercuspation of the posterior teeth \\
\hline $\begin{array}{l}\text { MP. } \\
\text { Mandibular } \\
\text { plane }\end{array}$ & Passing through Me, tangent to the lower border of mandible \\
\hline Measurements & Definition \\
\hline L Volume & L Volume \\
\hline R Volume & R Volume \\
\hline 6-MD & $\begin{array}{l}\text { Sagittally discrepancy of both arches, the distance between the projection of mesiobuccal cusp of } \\
\text { upper first molar and mesiobuccal groove of lower first molar to the OP }\end{array}$ \\
\hline $\begin{array}{l}\text { R: } \\
\angle \text { U6/Coronal }\end{array}$ & The angulation of the angle formed by the long axes of right upper first molar and the coronal plane \\
\hline U6-PP & Distance between the mesiobuccal root apex of upper first molar and PP \\
\hline L6-MP & Distance between the mesiobuccal root apex of lower first molar and MP \\
\hline U1-PP & Distance between the incisal edge of upper central incisor and PP \\
\hline
\end{tabular}

Page 9/25 


\begin{tabular}{|c|c|}
\hline L1-MP & Distance between the incisal edge of lower central incisor and MP \\
\hline $\mathrm{J}-\mathrm{J}$ & Maxillary width, transverse width at the bilateral interjugular point \\
\hline AG-AG & Mandibular width, transverse width at the antegonial notch point \\
\hline $\begin{array}{l}\text { MxMn } \\
\text { difference }\end{array}$ & The difference between the AG-AG and J-J width \\
\hline U6-AC & Transverse width at the alveolar crest of bilateral maxillary first molar \\
\hline U6-MR & Transverse width at the alveolar crest of the midpoint of bilateral maxillary first molar root length \\
\hline U6-BLW & $\begin{array}{l}\text { Buccolingual width at the alveolar crest of bilateral maxillary upper first molar, the difference between } \\
\text { buccal and lingual AC transverse widths divided by } 2\end{array}$ \\
\hline U6MR-BLW & $\begin{array}{l}\text { Buccolingual width at the alveolar crest of the midpoint of bilateral maxillary upper first molar root } \\
\text { length, the difference between buccal and lingual AC transverse widths at midpoint root length divided } \\
\text { by } 2\end{array}$ \\
\hline U6-IM & $\begin{array}{l}\text { Transverse width between the most prominent points on the buccal surface of bilateral maxillary first } \\
\text { molar }\end{array}$ \\
\hline L: $\angle$ U6/Sagittal & The angulation of the angle formed by the long axes of left upper first molar and the sagittal plane \\
\hline Co-Go & Ramus height \\
\hline S-Go & Total posterior facial height \\
\hline $\mathrm{N}-\mathrm{Me}$ & Total anterior facial height \\
\hline ANS-Me & Lower anterior facial height \\
\hline U6-PP & Distance between the mesiobuccal root apex of upper first molar and PP \\
\hline L6-MP & Distance between the mesiobuccal root apex of lower first molar and MP \\
\hline U1-PP & Distance between the root apex of upper central incisor and PP \\
\hline L1-MP & Distance between the root apex of lower central incisor and MP \\
\hline Go-Me & Mandibular body length \\
\hline Co-Me & Total mandibular length \\
\hline$\angle U 1-S N$ & Maxillary incisor to SN plane angle \\
\hline$\angle \mathrm{IMPA}$ & Mandibular incisor to mandibular plane angle \\
\hline$\angle \mathrm{U} 1-\mathrm{LI}$ & Interincisal angle \\
\hline
\end{tabular}

Table 2

Comparison of bilateral condylar volume differences among each group. 


\begin{tabular}{lllll} 
Group & L Volume $\left(\mathrm{mm}^{3}\right)$ & R Volume $\left(\mathrm{mm}^{3}\right)$ & t & P \\
\hline All & $1108.93 \pm 484.14$ & $1155.99 \pm 513.18$ & -1.363 & 0.196 \\
\hline Normal & $1794.64 \pm 305.87$ & $1764.93 \pm 235.79$ & 0.522 & 0.611 \\
\hline Resorption & $1244.73 \pm 383.05$ & $1319.48 \pm 421.28$ & -1.478 & 0.162 \\
\hline Flattening & $1056.23 \pm 284.53$ & $1098.58 \pm 262.01$ & -1.251 & 0.230 \\
\hline Osteophyte & $1108.93 \pm 484.14$ & $1155.99 \pm 513.18$ & -1.363 & 0.196 \\
\hline
\end{tabular}

Values do not differ significantly (Pख0.05).

Table 3

Comparison of the condylar volume differences between four groups.

\begin{tabular}{|c|c|c|c|c|c|c|}
\hline Variables & Normal & Resorption & Flattening & Osteophyte & $\mathrm{F}$ & $\mathbf{P}$ \\
\hline $\begin{array}{l}\mathrm{L} \\
\text { Volume }\left(\mathrm{mm}^{3}\right)\end{array}$ & $1794.64 \pm 305.87 \#$ & $1244.73 \pm 383.05^{\star}$ & $1056.23 \pm 284.53^{*}$ & $1108.93 \pm 484.14$ * & 11.998 & 0.004 \\
\hline $\begin{array}{l}R \\
\text { Volume }\left(\mathrm{mm}^{3}\right)\end{array}$ & $1764.93 \pm 235.79 \#$ & $1319.48 \pm 421.28^{\star}$ & $1098.58 \pm 262.01^{*}$ & $1155.99 \pm 513.18^{*}$ & 9.045 & 0.020 \\
\hline $\begin{array}{l}\text { Average } \\
\text { Volume }\left(\mathrm{mm}^{3}\right)\end{array}$ & $1779.78 \pm 251.46 \#$ & $1282.10 \pm 390.53^{*}$ & $1077.41 \pm 264.98^{*}$ & $1132.46 \pm 494.68^{*}$ & 11.238 & 0.012 \\
\hline
\end{tabular}

${ }^{*} \mathrm{P}<0.05 / 6$ when compare to normal group; $\# \mathrm{P}<0.05 / 6$ when compare to resorption group; $\mathrm{P}<0.05 / 6$ when compare to flattening group; $\varangle \mathrm{P}<0.05 / 6$ when compare to osteophyte group.

Table 4

Comparison of vertical measurements and measurements related to condylar volume. 


\begin{tabular}{|c|c|c|c|c|c|c|c|c|}
\hline \multirow[t]{2}{*}{ Variables } & \multirow[t]{2}{*}{ Normal } & \multicolumn{3}{|l|}{ Pathological } & \multirow[t]{2}{*}{$F$} & \multirow[t]{2}{*}{$\mathbf{P}$} & \multirow[t]{2}{*}{$\mathbf{r}$} & \multirow[t]{2}{*}{ p } \\
\hline & & Resorption & Flattening & Osteophyte & & & & \\
\hline$\angle \mathrm{SN}-\mathrm{PP}\left({ }^{\circ}\right)$ & $9.51 \pm 1.02$ & $10.33 \pm 0.85$ & $10.41 \pm 0.71$ & $11.09 \pm 0.81$ & 0.554 & 0.648 & -0.043 & 0.745 \\
\hline$\angle \mathrm{SN}-\mathrm{OP}\left(^{\circ}\right)$ & $21.84 \pm 0.98$ & $25.42 \pm 1.08$ & $27.58 \pm 1.50$ & $25.06 \pm 1.22$ & 5.746 & $0.002 \#$ & -0.394 & $0.002 *$ \\
\hline$\angle \mathrm{SN}-\mathrm{MP}\left({ }^{\circ}\right)$ & $42.39 \pm 0.92$ & $47.82 \pm 0.75$ & $48.97 \pm 2.07$ & $48.56 \pm 1.48$ & 5.266 & $0.003 \#$ & -0.423 & $0.001^{*}$ \\
\hline$\angle \mathrm{FMA}\left(\left(^{\circ}\right)\right.$ & $30.44 \pm 0.81$ & $34.84 \pm 1.02$ & $35.71 \pm 1.71$ & $35.03 \pm 1.29$ & 4.592 & $0.006 \#$ & -0.509 & $0.000 *$ \\
\hline$\angle \mathrm{PP}-\mathrm{MP}\left({ }^{\circ}\right)$ & $33.25 \pm 1.36$ & $33.99 \pm 1.16$ & $38.41 \pm 2.06$ & $37.87 \pm 1.52$ & 2.730 & 0.053 & -0.436 & $0.001^{*}$ \\
\hline Co-Go (mm) & $59.63 \pm 1.13$ & $56.21 \pm 1.45$ & $51.92 \pm 1.06$ & $51.87 \pm 1.70$ & 7.609 & $0.000 \#$ & 0.765 & $0.000 *$ \\
\hline S-Go (mm) & $80.77 \pm 1.51$ & $78.39 \pm 1.25$ & $75.1 \pm 1.76$ & $72.91 \pm 1.72$ & 4.685 & $0.006 \#$ & 0.573 & $0.000 *$ \\
\hline $\mathrm{N}-\mathrm{Me}(\mathrm{mm})$ & $129.19 \pm 1.49$ & $128.29 \pm 1.01$ & $130.21 \pm 1.43$ & $129.68 \pm 1.75$ & 0.334 & 0.801 & 0.249 & 0.057 \\
\hline ANS-Me (mm) & $75.56 \pm 1.09$ & $74.19 \pm 0.93$ & $76.57 \pm 1.35$ & $76.49 \pm 1.58$ & 0.781 & 0.509 & 0.181 & 0.171 \\
\hline $\mathrm{S}-\mathrm{Go} / \mathrm{N}-\mathrm{Me}$ & $0.63 \pm 0.01$ & $0.61 \pm 0.01$ & $0.58 \pm 0.01$ & $0.56 \pm 0.01$ & 6.563 & $0.001 \#$ & 0.466 & $0.000 *$ \\
\hline ANS-Me/ N-Me & $0.58 \pm 0.01$ & $0.58 \pm 0.01$ & $0.59 \pm 0.01$ & $0.59 \pm 0.01$ & 0.557 & 0.646 & -0.024 & 0.855 \\
\hline U6-PP (mm) & $6.83 \pm 0.38$ & $6.16 \pm 0.52$ & $5.68 \pm 0.36$ & $5.95 \pm 0.6$ & 1.074 & 0.368 & -0.449 & $0.000 *$ \\
\hline L6-MP (mm) & $16.06 \pm 0.57$ & $15.67 \pm 0.6$ & $16.16 \pm 0.91$ & $15.34 \pm 0.84$ & 0.244 & 0.865 & -0.337 & $0.009 *$ \\
\hline U1-PP (mm) & $11.03 \pm 0.71$ & $10.51 \pm 0.5$ & $10.4 \pm 0.46$ & $10.09 \pm 0.44$ & 0.516 & 0.673 & 0.035 & 0.792 \\
\hline L1-MP (mm) & $25.37 \pm 0.83$ & $23.51 \pm 0.63$ & $24.71 \pm 1.03$ & $23.25 \pm 1.04$ & 1.197 & 0.319 & -0.308 & $0.018 *$ \\
\hline Overbite (mm) & $4.46 \pm 0.5$ & $2.65 \pm 0.71$ & $2.06 \pm 0.81$ & $2.73 \pm 0.74$ & 2.085 & 0.113 & 0.203 & 0.124 \\
\hline
\end{tabular}

$\# P<0.05 ;{ }^{\star} \mathrm{p}<0.05$.

Table 5

Comparison of sagittal measurements and measurements related to condylar volume. 


\begin{tabular}{|c|c|c|c|c|c|c|c|c|}
\hline \multirow{2}{*}{ Variables } & \multirow[t]{2}{*}{ Normal } & \multicolumn{3}{|l|}{ Pathological } & \multirow[t]{2}{*}{$F$} & \multirow[t]{2}{*}{$\mathbf{P}$} & \multirow[t]{2}{*}{$r$} & \multirow[t]{2}{*}{ p } \\
\hline & & Resorption & Flattening & Osteophyte & & & & \\
\hline$\angle S N A\left({ }^{\circ}\right)$ & $81.26 \pm 1.34$ & $81.06 \pm 1.27$ & $81.53 \pm 1.54$ & $83.02 \pm 1.18$ & 1.843 & 0.749 & 0.426 & 0.285 \\
\hline$\angle \mathrm{SNB}\left({ }^{\circ}\right)$ & $74.92 \pm 1.75$ & $74.81 \pm 1.82$ & $73.26 \pm 1.37$ & $71.73 \pm 1.52$ & 1.472 & $0.036 \#$ & 0.649 & $0.001^{*}$ \\
\hline$\angle \mathrm{ANB}\left(^{\circ}\right)$ & $6.93 \pm 0.48$ & $6.97 \pm 0.66$ & $7.56 \pm 0.43$ & $9.02 \pm 0.65$ & 2.920 & $0.042 \#$ & -0.328 & $0.011^{*}$ \\
\hline Go-Me (mm) & $67.61 \pm 1.12$ & $67.63 \pm 1.01$ & $67.79 \pm 1.43$ & $67.92 \pm 0.79$ & 0.016 & 0.997 & 0.137 & 0.300 \\
\hline Co-Me (mm) & $111.71 \pm 1.21$ & $109.03 \pm 1.39$ & $105.56 \pm 1.01$ & $98.86 \pm 7.7$ & 2.046 & 0.118 & 0.745 & $0.000^{*}$ \\
\hline L: 6-MD (mm) & $1.93 \pm 0.22$ & $2.47 \pm 0.35$ & $1.81 \pm 0.22$ & $2.31 \pm 0.33$ & 1.204 & 0.317 & -0.143 & 0.281 \\
\hline $\mathrm{R}:$ 6-MD (mm) & $2.14 \pm 0.2$ & $2.9 \pm 0.46$ & $1.99 \pm 0.28$ & $2.94 \pm 0.51$ & 1.727 & 0.172 & -0.137 & 0.302 \\
\hline $\begin{array}{l}\mathrm{L}: \angle \mathrm{U} 7 / \text { Coronal } \\
\left({ }^{\circ}\right)\end{array}$ & $-10.14 \pm 2.71$ & $-9.15 \pm 2.73$ & $-14.14 \pm 3$ & $-12.35 \pm 2.38$ & 0.693 & 0.560 & 0.501 & 0.257 \\
\hline $\begin{array}{l}\mathrm{L}: \angle \mathrm{U} 6 / \text { Coronal } \\
\left(^{\circ}\right)\end{array}$ & $-5.01 \pm 1.92$ & $-2.59 \pm 1.72$ & $-8.21 \pm 2.38$ & $-8.41 \pm 1.23$ & 2.177 & 0.101 & 0.363 & 0.395 \\
\hline $\begin{array}{l}\mathrm{L}: \angle \mathrm{U} 5 / \text { Coronal } \\
\left({ }^{\circ}\right)\end{array}$ & $-3.41 \pm 2.11$ & $-2.77 \pm 1.33$ & $-5.73 \pm 2.26$ & $-5.9 \pm 1.02$ & 0.793 & 0.503 & 0.338 & 0.189 \\
\hline $\begin{array}{l}\mathrm{L}: \angle \mathrm{U} 4 / \text { Coronal } \\
\left(^{\circ}\right)\end{array}$ & $5.37 \pm 2.08$ & $5.72 \pm 1.25$ & $1.77 \pm 1.94$ & $-0.74 \pm 1.42$ & 3.142 & $0.032 \#$ & 0.401 & 0.212 \\
\hline $\begin{array}{l}\mathrm{L}: \angle \mathrm{L} 7 / \text { Coronal } \\
\left({ }^{\circ}\right)\end{array}$ & $30.64 \pm 1.57$ & $29.77 \pm 2.17$ & $34.68 \pm 2.35$ & $34.85 \pm 1.81$ & 1.713 & 0.175 & -0.405 & $0.001^{*}$ \\
\hline $\begin{array}{l}\mathrm{L}: \angle \mathrm{L} 6 / \text { Coronal } \\
\left({ }^{\circ}\right)\end{array}$ & $27.84 \pm 1.51$ & $27.88 \pm 1.9$ & $30.76 \pm 2.25$ & $30.66 \pm 1.26$ & 0.822 & 0.487 & -0.512 & $0.000^{*}$ \\
\hline $\begin{array}{l}\mathrm{L}: \angle \mathrm{L} 5 / \text { Coronal } \\
\left(^{\circ}\right)\end{array}$ & $25.74 \pm 1.39$ & $28.1 \pm 1.92$ & $30.66 \pm 2.27$ & $28.64 \pm 1.54$ & 1.201 & 0.318 & -0.553 & $0.000^{\star}$ \\
\hline $\begin{array}{l}\mathrm{L}: \angle \mathrm{L} 4 / \text { Coronal } \\
\left({ }^{\circ}\right)\end{array}$ & $23.89 \pm 1.93$ & $26.68 \pm 1.98$ & $30.59 \pm 2.08$ & $28.1 \pm 1.76$ & 2.070 & 0.115 & -0.443 & $0.000^{*}$ \\
\hline $\begin{array}{l}\text { R: } \angle U 7 / \text { Coronal } \\
\left({ }^{\circ}\right)\end{array}$ & $-10.29 \pm 2.4$ & $-11.21 \pm 3.2$ & $-18.07 \pm 2.77$ & $-14.29 \pm 2.05$ & 1.786 & 0.161 & 0.436 & 0.171 \\
\hline $\begin{array}{l}\text { R: } \angle \text { U6/Coronal } \\
\left({ }^{\circ}\right)\end{array}$ & $-4.34 \pm 2.24$ & $-2.91 \pm 1.43$ & $-8.24 \pm 2.77$ & $-7.07 \pm 1.17$ & 1.459 & 0.236 & 0.441 & 0.380 \\
\hline $\begin{array}{l}\text { R: } \angle \text { U5/Coronal } \\
\left({ }^{\circ}\right)\end{array}$ & $-4.7 \pm 1.78$ & $-1.94 \pm 1.73$ & $-4.78 \pm 2.3$ & $-2.07 \pm 1.17$ & 0.745 & 0.530 & 0.289 & 0.226 \\
\hline $\begin{array}{l}\text { R: } \angle U 4 / \text { Coronal } \\
\left({ }^{\circ}\right)\end{array}$ & $2.85 \pm 1.68$ & $5.87 \pm 1.5$ & $2.08 \pm 2.07$ & $2.47 \pm 1.05$ & 1.128 & 0.346 & 0.256 & 0.150 \\
\hline $\begin{array}{l}\text { R: } \angle \mathrm{L} 7 / \text { Coronal } \\
\left(^{\circ}\right)\end{array}$ & $28.99 \pm 1.7$ & $30.72 \pm 2.5$ & $32.79 \pm 2.42$ & $33.17 \pm 1.64$ & 0.800 & 0.499 & -0.400 & $0.002^{\star}$ \\
\hline $\begin{array}{l}\text { R: } \angle \text { L6/Coronal } \\
\left({ }^{\circ}\right)\end{array}$ & $25.85 \pm 1.14$ & $27.57 \pm 2.16$ & $32.16 \pm 2.27$ & $29.56 \pm 1.38$ & 2.179 & 0.101 & -0.530 & $0.000^{*}$ \\
\hline $\begin{array}{l}\text { R: } \angle \text { L5/Coronal } \\
\left(^{\circ}\right)\end{array}$ & $25.43 \pm 1.69$ & $26.15 \pm 1.69$ & $30.11 \pm 2.27$ & $27.96 \pm 1.55$ & 1.306 & 0.282 & -0.580 & $0.000^{*}$ \\
\hline $\begin{array}{l}\text { R: } \angle \text { L4/Coronal } \\
\left(^{\circ}\right)\end{array}$ & $24.06 \pm 2.03$ & $27.14 \pm 1.72$ & $30.85 \pm 2.2$ & $29.57 \pm 2.08$ & 2.173 & 0.102 & -0.385 & $0.003^{\star}$ \\
\hline$\angle \mathrm{U} 1-\mathrm{SN}\left({ }^{\circ}\right)$ & $104.36 \pm 2.18$ & $106.25 \pm 2.13$ & $105.01 \pm 2.18$ & $105.36 \pm 1.11$ & 0.155 & 0.926 & 0.004 & 0.976 \\
\hline$\angle \mathrm{IMPA}\left({ }^{\circ}\right)$ & $98.42 \pm 1.6$ & $107.12 \pm 1.2$ & $\begin{array}{r}105.87 \pm 1.11 \\
\text { Page 13/25 }\end{array}$ & $106.16 \pm 1.49$ & 4.656 & 0.087 & -0.321 & $0.035^{\star}$ \\
\hline
\end{tabular}




\begin{tabular}{|c|c|c|c|c|c|c|c|c|}
\hline$\angle \mathrm{U} 1-\mathrm{L} 1\left(^{\circ}\right)$ & $115.93 \pm 2.84$ & $108.07 \pm 2.15$ & $108.33 \pm 1.34$ & $108.15 \pm 1.43$ & 3.351 & $0.025 \#$ & 0.274 & $0.036 *$ \\
\hline Overjet (mm) & $2.58 \pm 0.37$ & $4.32 \pm 0.7$ & $4.37 \pm 0.53$ & $4.47 \pm 0.44$ & 2.590 & $0.042 \#$ & -0.376 & $0.003^{*}$ \\
\hline
\end{tabular}

$\# P<0.05 ;{ }^{*} \mathrm{p}<0.05$.

Table 6

Comparison of transversal measurements and measurements related to condylar volume 


\begin{tabular}{|c|c|c|c|c|c|c|c|c|}
\hline \multirow[t]{2}{*}{ Variables } & \multirow[t]{2}{*}{ Normal } & \multicolumn{3}{|l|}{ Pathological } & \multirow[t]{2}{*}{$F$} & \multirow[t]{2}{*}{$\mathbf{P}$} & \multirow[t]{2}{*}{$\mathbf{r}$} & \multirow[t]{2}{*}{$\mathrm{p}$} \\
\hline & & Resorption & Flattening & Osteophyte & & & & \\
\hline Max: J-J (mm) & $64.19 \pm 0.82$ & $64.12 \pm 0.88$ & $64.76 \pm 0.85$ & $63.59 \pm 0.52$ & 0.712 & 0.549 & -0.058 & 0.661 \\
\hline $\begin{array}{l}\text { Man: AG-AG } \\
(\mathrm{mm})\end{array}$ & $84.1 \pm 1.00$ & $84.79 \pm 1.75$ & $86.96 \pm 1.11$ & $83.9 \pm 53.68$ & 1.055 & 0.376 & -0.156 & 0.238 \\
\hline Man-Max (mm) & $10.17 \pm 0.53$ & $10.36 \pm 0.69$ & $11.69 \pm 0.34$ & $10.06 \pm 0.28$ & 0.824 & 0.518 & -0.061 & 0.647 \\
\hline U7-AC (mm) & $61.12 \pm 0.81$ & $61.23 \pm 0.8$ & $61.96 \pm 0.85$ & $60.7 \pm 0.77$ & 0.432 & 0.731 & -0.037 & 0.782 \\
\hline U7-MR (mm) & $59.35 \pm 4.12$ & $63.2 \pm 0.76$ & $64.15 \pm 0.95$ & $62.64 \pm 0.63$ & 0.992 & 0.404 & -0.017 & 0.900 \\
\hline U7-BLW (mm) & $12.43 \pm 0.82$ & $11.29 \pm 0.45$ & $11.75 \pm 1.16$ & $12.36 \pm 0.73$ & -0.621 & 0.764 & -0.117 & 0.378 \\
\hline $\begin{array}{l}\text { U7MR-BLW } \\
(\mathrm{mm})\end{array}$ & $13.93 \pm 0.47$ & $10.85 \pm 0.71$ & $10.95 \pm 0.84$ & $10.45 \pm 0.62$ & -3.248 & 0.029\# & -0.023 & 0.861 \\
\hline U6-AC (mm) & $57.44 \pm 0.59$ & $56.39 \pm 0.83$ & $54.54 \pm 3.37$ & $57.27 \pm 0.61$ & 0.493 & 0.689 & -0.073 & 0.584 \\
\hline U6-MR (mm) & $62.59 \pm 0.79$ & $61.33 \pm 0.93$ & $62.44 \pm 0.81$ & $61.24 \pm 0.57$ & 0.796 & 0.501 & 0.032 & 0.811 \\
\hline U6-BLW (mm) & $11.54 \pm 0.23$ & $10.89 \pm 0.47$ & $11.08 \pm 0.17$ & $10.95 \pm 0.35$ & -0.407 & 0.518 & 0.293 & $0.024 *$ \\
\hline $\begin{array}{l}\text { U6MR-BLW } \\
(\mathrm{mm})\end{array}$ & $17.02 \pm 0.71$ & $14.82 \pm 0.83$ & $15.36 \pm 1.02$ & $14.91 \pm 0.49$ & -3.617 & 0.075 & 0.136 & 0.305 \\
\hline U5-AC (mm) & $50.74 \pm 0.6$ & $50.24 \pm 0.81$ & $50.78 \pm 0.7$ & $84.29 \pm 33.37$ & 1.096 & 0.358 & -0.031 & 0.813 \\
\hline U5-MR (mm) & $54.29 \pm 0.76$ & $53.43 \pm 0.79$ & $54.28 \pm 0.67$ & $53.89 \pm 0.49$ & 0.346 & 0.792 & 0.043 & 0.749 \\
\hline U5-BLW (mm) & $9.27 \pm 0.94$ & $8.34 \pm 0.53$ & $8.79 \pm 0.82$ & $7.86 \pm 0.52$ & -1.187 & 0.611 & -0.218 & 0.097 \\
\hline $\begin{array}{l}\text { U5MR-BLW } \\
(\mathrm{mm})\end{array}$ & $12.06 \pm 0.42$ & $10.17 \pm 0.68$ & $9.97 \pm 0.71$ & $11.26 \pm 0.81$ & -0.629 & 0.396 & 0.048 & 0.720 \\
\hline U4-AC (mm) & $45.46 \pm 0.56$ & $45.07 \pm 0.72$ & $72.01 \pm 27.34$ & $45.76 \pm 0.41$ & 0.842 & 0.477 & -0.067 & 0.613 \\
\hline U4-MR (mm) & $48.56 \pm 0.82$ & $47.26 \pm 1.03$ & $47.7 \pm 0.67$ & $49.37 \pm 0.97$ & 1.130 & 0.345 & 0.007 & 0.955 \\
\hline U4-BLW (mm) & $7.59 \pm 0.64$ & $7.85 \pm 1.38$ & $7.74 \pm 0.83$ & $7.82 \pm 0.98$ & -1.026 & 0.472 & -0.195 & 0.140 \\
\hline $\begin{array}{l}\text { U4MR-BLW } \\
(\mathrm{mm})\end{array}$ & $11.69 \pm 0.84$ & $9.64 \pm 0.68$ & $10.65 \pm 0.79$ & $11.65 \pm 1.31$ & -0.993 & 0.892 & -0.128 & 0.333 \\
\hline L7-AC (mm) & $62.21 \pm 0.56$ & $62.41 \pm 0.6$ & $62.48 \pm 0.5$ & $102.06 \pm 39.69$ & 1.074 & 0.368 & -0.062 & 0.639 \\
\hline L7-MR (mm) & $77.21 \pm 1.11$ & $77.93 \pm 1.04$ & $76.57 \pm 1.25$ & $76.71 \pm 1.47$ & 0.259 & 0.855 & -0.081 & 0.544 \\
\hline L7-BLW (mm) & $8.97 \pm 0.87$ & $8.21 \pm 0.78$ & $9.28 \pm 0.74$ & $8.54 \pm 0.94$ & -1.174 & 0.923 & 0.118 & 0.372 \\
\hline $\begin{array}{l}\text { L7MR-BLW } \\
(\mathrm{mm})\end{array}$ & $16.47 \pm 0.72$ & $16.95 \pm 0.83$ & $17.97 \pm 0.69$ & $16.91 \pm 0.53$ & -0.244 & 0.459 & -0.047 & 0.724 \\
\hline L6-AC (mm) & $55.24 \pm 0.38$ & $55.97 \pm 0.55$ & $56.21 \pm 0.67$ & $55.54 \pm 0.67$ & 0.556 & 0.646 & -0.369 & $0.039 *$ \\
\hline L6-MR (mm) & $59.03 \pm 0.66$ & $59.85 \pm 0.85$ & $59.29 \pm 1.03$ & $60.23 \pm 1.22$ & 0.304 & 0.823 & -0.201 & 0.127 \\
\hline L6-BLW (mm) & $8.29 \pm 0.33$ & $8.19 \pm 0.38$ & $8.49 \pm 0.71$ & $8.55 \pm 0.72$ & -1.147 & 0.341 & 0.065 & 0.627 \\
\hline $\begin{array}{l}\text { L6MR-BLW } \\
(\mathrm{mm})\end{array}$ & $12.97 \pm 0.42$ & $10.94 \pm 0.61$ & $11.02 \pm 0.58$ & $10.32 \pm 0.82$ & -3.601 & $0.027 \#$ & -0.066 & 0.619 \\
\hline L5-AC (mm) & $46.61 \pm 0.6$ & $47.36 \pm 0.8$ & $44.19 \pm 2.74$ & $46.3 \pm 0.52$ & 0.774 & 0.514 & -0.083 & 0.530 \\
\hline L5-MR (mm) & $48.96 \pm 0.52$ & $48.98 \pm 0.64$ & $49.8 \pm 0.85$ & $48.69 \pm 0.61$ & 0.515 & 0.673 & -0.122 & 0.357 \\
\hline
\end{tabular}




\begin{tabular}{|c|c|c|c|c|c|c|c|c|}
\hline L5-BLW (mm) & $7.49 \pm 0.85$ & $6.71 \pm 0.88$ & $7.18 \pm 0.43$ & $6.74 \pm 0.46$ & -1.71 & 0.262 & 0.107 & 0.421 \\
\hline $\begin{array}{l}\text { L5MR-BLW } \\
(\mathrm{mm})\end{array}$ & $9.8 \pm 0.83$ & $9.17 \pm 0.91$ & $10.01 \pm 0.50$ & $9.75 \pm 0.54$ & -0.937 & 0.176 & -0.114 & 0.390 \\
\hline L4-AC (mm) & $39.51 \pm 0.43$ & $39.08 \pm 0.62$ & $38.53 \pm 0.78$ & $39.26 \pm 0.52$ & 0.466 & 0.707 & -0.078 & 0.556 \\
\hline L4-MR (mm) & $40.5 \pm 0.44$ & $40.36 \pm 0.74$ & $41.11 \pm 0.67$ & $40.54 \pm 0.53$ & 0.306 & 0.821 & -0.187 & 0.155 \\
\hline L4-BLW (mm) & $6.77 \pm 0.83$ & $5.81 \pm 1.14$ & $6.55 \pm 0.76$ & $6.1 \pm 0.68$ & -0.902 & 0.674 & 0.153 & 0.248 \\
\hline $\begin{array}{l}\text { L4MR-BLW } \\
(\mathrm{mm})\end{array}$ & $10.78 \pm 0.64$ & $10.75 \pm 0.69$ & $10.1 \pm 0.86$ & $10.35 \pm 0.74$ & -1.523 & 0.528 & -0.191 & 0.148 \\
\hline U7-IM (mm) & $60.55 \pm 0.8$ & $61.34 \pm 0.91$ & $61.29 \pm 0.73$ & $61.2 \pm 0.65$ & 0.215 & 0.886 & -0.046 & 0.727 \\
\hline U6-IM (mm) & $55.72 \pm 0.16$ & $55.93 \pm 0.76$ & $56.54 \pm 0.76$ & $55.8 \pm 0.65$ & 1.055 & 0.376 & 0.098 & 0.460 \\
\hline U5-IM (mm) & $50.51 \pm 0.48$ & $50.64 \pm 0.85$ & $51.03 \pm 0.76$ & $50.3 \pm 0.59$ & 0.197 & 0.898 & 0.089 & 0.500 \\
\hline U4-IM (mm) & $45.09 \pm 0.45$ & $45.17 \pm 0.66$ & $45.34 \pm 0.69$ & $42.05 \pm 0.72$ & 0.828 & 0.484 & 0.065 & 0.625 \\
\hline L7-IM (mm) & $57.48 \pm 0.68$ & $58.08 \pm 0.72$ & $58 \pm 0.73$ & $58.04 \pm 0.59$ & 0.164 & 0.920 & -0.164 & 0.214 \\
\hline L6-IM (mm) & $50.25 \pm 0.55$ & $50.83 \pm 0.82$ & $51.05 \pm 0.78$ & $49.41 \pm 0.87$ & 0.905 & 0.445 & -0.323 & $0.029 *$ \\
\hline L5-IM (mm) & $44.65 \pm 0.55$ & $45.31 \pm 0.88$ & $45.41 \pm 0.75$ & $44.25 \pm 0.64$ & 0.573 & 0.635 & -0.185 & 0.160 \\
\hline L4-IM (mm) & $38.36 \pm 0.53$ & $38.43 \pm 0.75$ & $38.53 \pm 0.6$ & $38.4 \pm 0.58$ & 0.014 & 0.998 & -0.039 & 0.767 \\
\hline $\begin{array}{l}\mathrm{L}: \\
\left({ }^{\circ}\right)\end{array}$ & $10.44 \pm 2.46$ & $14.8 \pm 2.49$ & $12.17 \pm 2.16$ & $10.84 \pm 1.74$ & 0.767 & 0.518 & -0.123 & 0.354 \\
\hline $\begin{array}{l}\mathrm{L}: \\
\left(\left(^{\circ}\right)\right.\end{array}$ & $1.41 \pm 1.91$ & $5.91 \pm 1.83$ & $5.17 \pm 1.96$ & $4.79 \pm 1.43$ & 1.173 & 0.328 & -0.222 & 0.091 \\
\hline $\begin{array}{l}\mathrm{L}: \\
\left({ }^{\circ}\right)\end{array}$ & $-2.86 \pm 1.56$ & $0.86 \pm 1.99$ & $-0.97 \pm 1.66$ & $-0.55 \pm 1.78$ & 0.744 & 0.531 & 0.214 & 0.103 \\
\hline $\begin{array}{l}\mathrm{L}: \\
\left(\left(^{\circ}\right)\right.\end{array}$ & $-3.69 \pm 2.05$ & $-2.51 \pm 1.82$ & $-1.63 \pm 1.37$ & $-2.71 \pm 1.71$ & 0.241 & 0.868 & 0.216 & 0.101 \\
\hline $\begin{array}{l}\text { R: } \angle U 7 / \text { Sagittal } \\
\left(\left(^{\circ}\right)\right.\end{array}$ & $9.35 \pm 1.84$ & $13.18 \pm 2.56$ & $10.63 \pm 3.15$ & $9.79 \pm 1.47$ & 0.520 & 0.670 & -0.023 & 0.863 \\
\hline $\begin{array}{l}\text { R: } \angle U 6 / \text { Sagittal } \\
\left(\left(^{\circ}\right)\right.\end{array}$ & $1.77 \pm 2.1$ & $4.8 \pm 1.95$ & $4.44 \pm 1.79$ & $2.7 \pm 1.21$ & 0.631 & 0.598 & -0.153 & 0.248 \\
\hline $\begin{array}{l}\mathrm{R}: \\
\left(^{\circ}\right)\end{array}$ & $2.44 \pm 2.14$ & $1.13 \pm 1.73$ & $1.08 \pm 2.02$ & $-0.43 \pm 1.35$ & 0.392 & 0.760 & 0.047 & 0.726 \\
\hline $\begin{array}{l}\text { R: } \angle U 4 / \text { Sagittal } \\
\left(\left(^{\circ}\right)\right.\end{array}$ & $0.63 \pm 2.14$ & $0.44 \pm 1.27$ & $-0.57 \pm 1.47$ & $-0.71 \pm 1.11$ & 0.197 & 0.898 & 0.158 & 0.231 \\
\hline $\begin{array}{l}\mathrm{L}: \angle \mathrm{L} 7 / \text { Sagittal } \\
\left(^{\circ}\right)\end{array}$ & $-22.48 \pm 2.18$ & $-22.81 \pm 2.95$ & $-18.17 \pm 4.91$ & $-19.37 \pm 2.05$ & 0.472 & 0.703 & 0.182 & 0.167 \\
\hline $\begin{array}{l}\mathrm{L}: \\
\left({ }^{\circ}\right)\end{array}$ & $-18.34 \pm 1.92$ & $-18.22 \pm 1.92$ & $-15.69 \pm 1.68$ & $-14.24 \pm 0.97$ & 1.390 & 0.256 & $\begin{array}{l}-0 . \\
380\end{array}$ & $0.037 *$ \\
\hline $\begin{array}{l}\mathrm{L}: \\
\left(\left(^{\circ}\right)\right.\end{array}$ & $-9.76 \pm 2.4$ & $-9.23 \pm 2.18$ & $-6.96 \pm 1.89$ & $-9.86 \pm 1.49$ & 0.471 & 0.704 & -0.132 & 0.321 \\
\hline $\begin{array}{l}\mathrm{L}: \\
\left({ }^{\circ}\right)\end{array}$ & $-1.83 \pm 2$ & $-2.63 \pm 2.3$ & $-0.2 \pm 2.32$ & $-4.11 \pm 1.5$ & 0.618 & 0.606 & 0.044 & 0.741 \\
\hline $\begin{array}{l}\text { R: } \angle L 7 / \text { Sagittal } \\
\left(\left(^{\circ}\right)\right.\end{array}$ & $-21.81 \pm 1.29$ & $-25.91 \pm 2.98$ & $-20.83 \pm 2.91$ & $-19.46 \pm 2.53$ & 1.200 & 0.319 & -0.230 & 0.080 \\
\hline
\end{tabular}




\begin{tabular}{|c|c|c|c|c|c|c|c|c|}
\hline $\begin{array}{l}\text { R: } \angle L 6 / \text { Sagittal } \\
\left(\left(^{\circ}\right)\right.\end{array}$ & $-17.55 \pm 1.65$ & $-18.34 \pm 1.56$ & $-16.69 \pm 2.13$ & $-14.99 \pm 1.89$ & 0.609 & 0.612 & $\begin{array}{l}-0 . \\
471\end{array}$ & $\begin{array}{l}0 . \\
015^{*}\end{array}$ \\
\hline $\begin{array}{l}\text { R: } \angle L 5 / \text { Sagittal } \\
\left(\left(^{\circ}\right)\right.\end{array}$ & $-6.03 \pm 4.72$ & $-9.05 \pm 2.13$ & $-7.94 \pm 1.83$ & $-9.93 \pm 1.95$ & 0.336 & 0.799 & -0.069 & 0.604 \\
\hline $\begin{array}{l}\text { R: } \angle \text { L4/Sagittal } \\
\left(^{\circ}\right)\end{array}$ & $-0.94 \pm 2.78$ & $-2.17 \pm 1.29$ & $-4.93 \pm 1.3$ & $-4.71 \pm 1.77$ & 1.105 & 0.355 & 0.096 & 0.472 \\
\hline
\end{tabular}

Man-Max: the difference between the AG-AG and J-J width; L: left; R: righr; IPM: inter-premolar width. $\# P<0.05 ; * p<0.05$

\section{Figures}

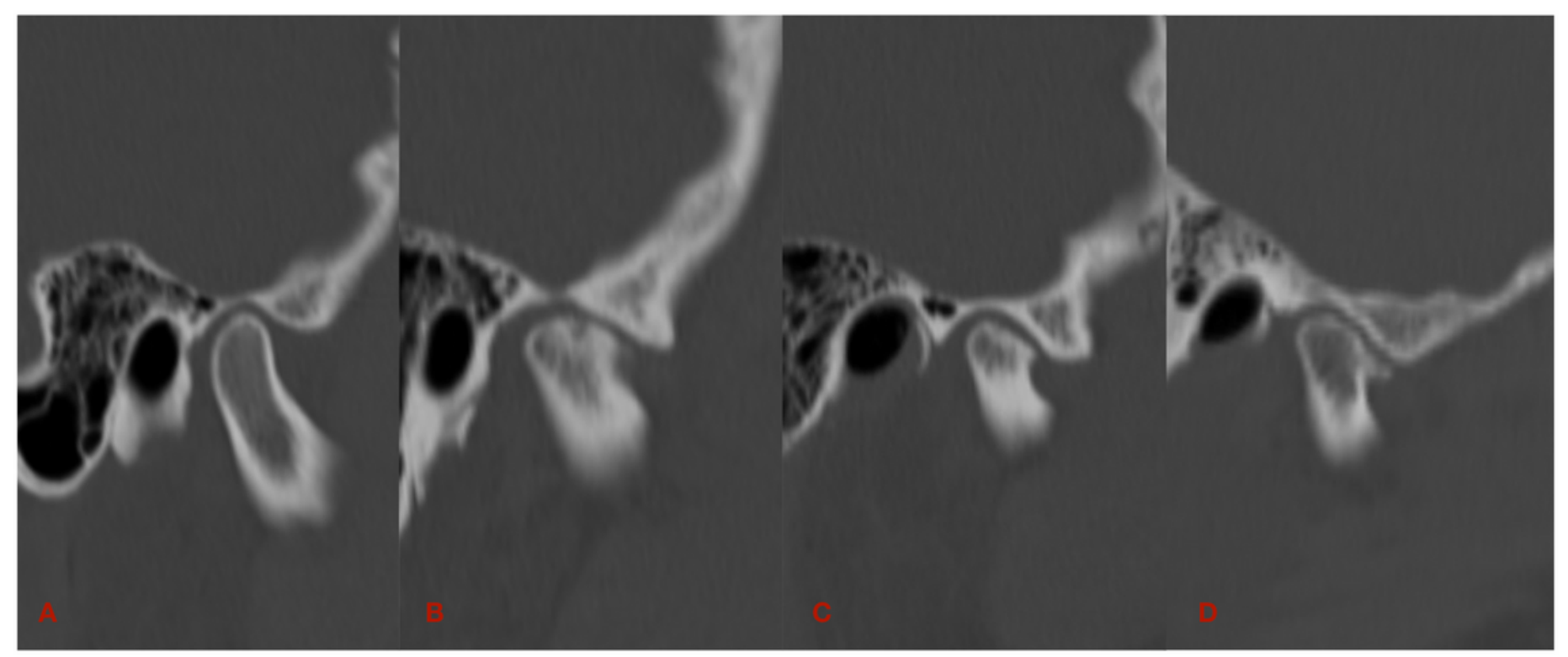

\section{Figure 1}

Sagittal view of four different types of condylar head bony morphologies: A, normal; B, resorption; C, flattening; D, osteophyte. 


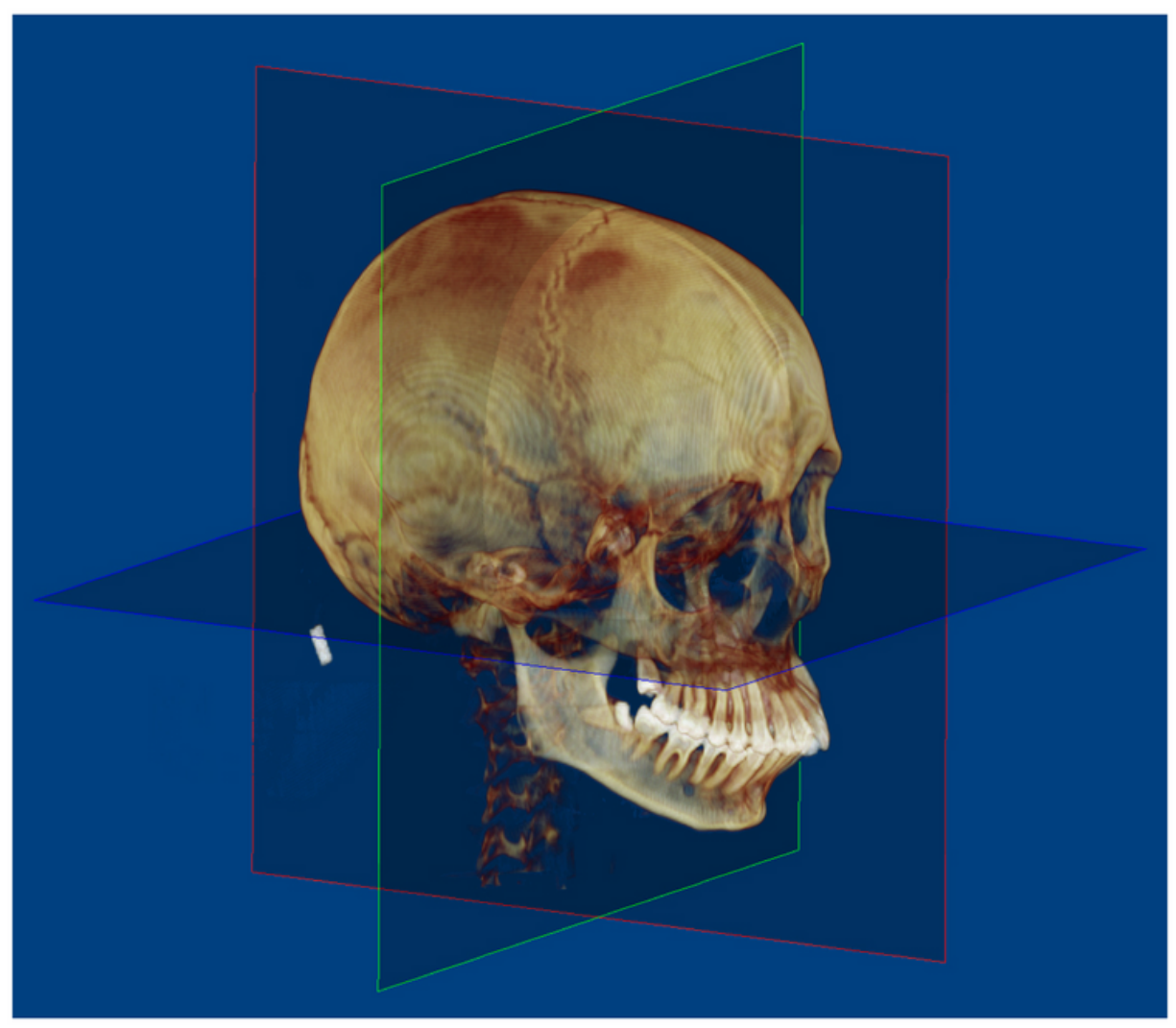

\section{Figure 2}

Reorientation based on reference planes. Blue: axial plane, FH plane; red: midsagittal plane, perpendicular to axial plane, passing through nasion and basion; green: coronal plane, perpendicular to the axial and coronal planes, passing through bilateral porions. 

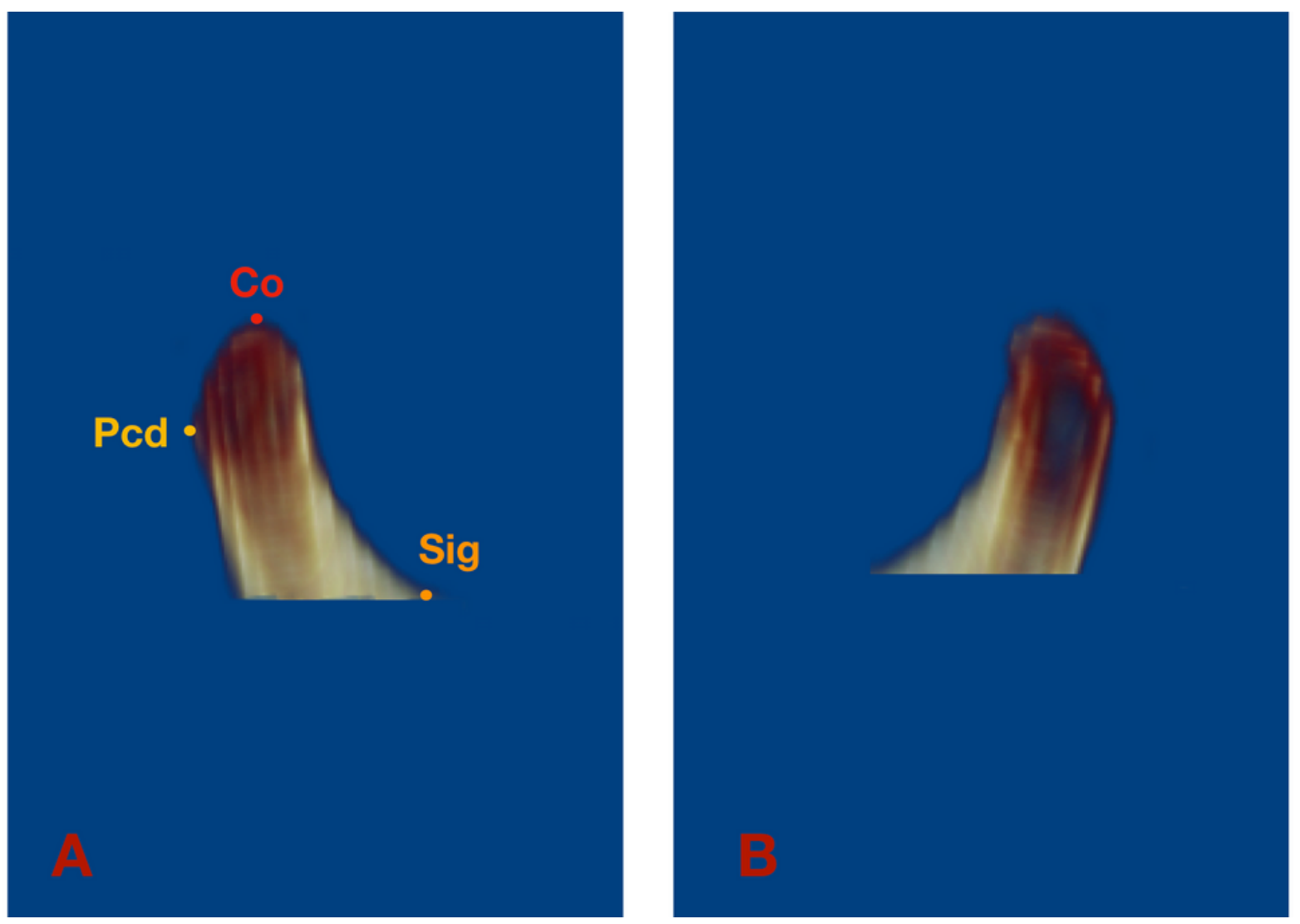

\section{Figure 3}

Sagittal view of unilateral condyle. A: right condyle; B: left condyle. Condylion (Co): most superior point of condyle; Pcd: Posterior condyle point; Sig: most inferior point of sigmoid notch. 


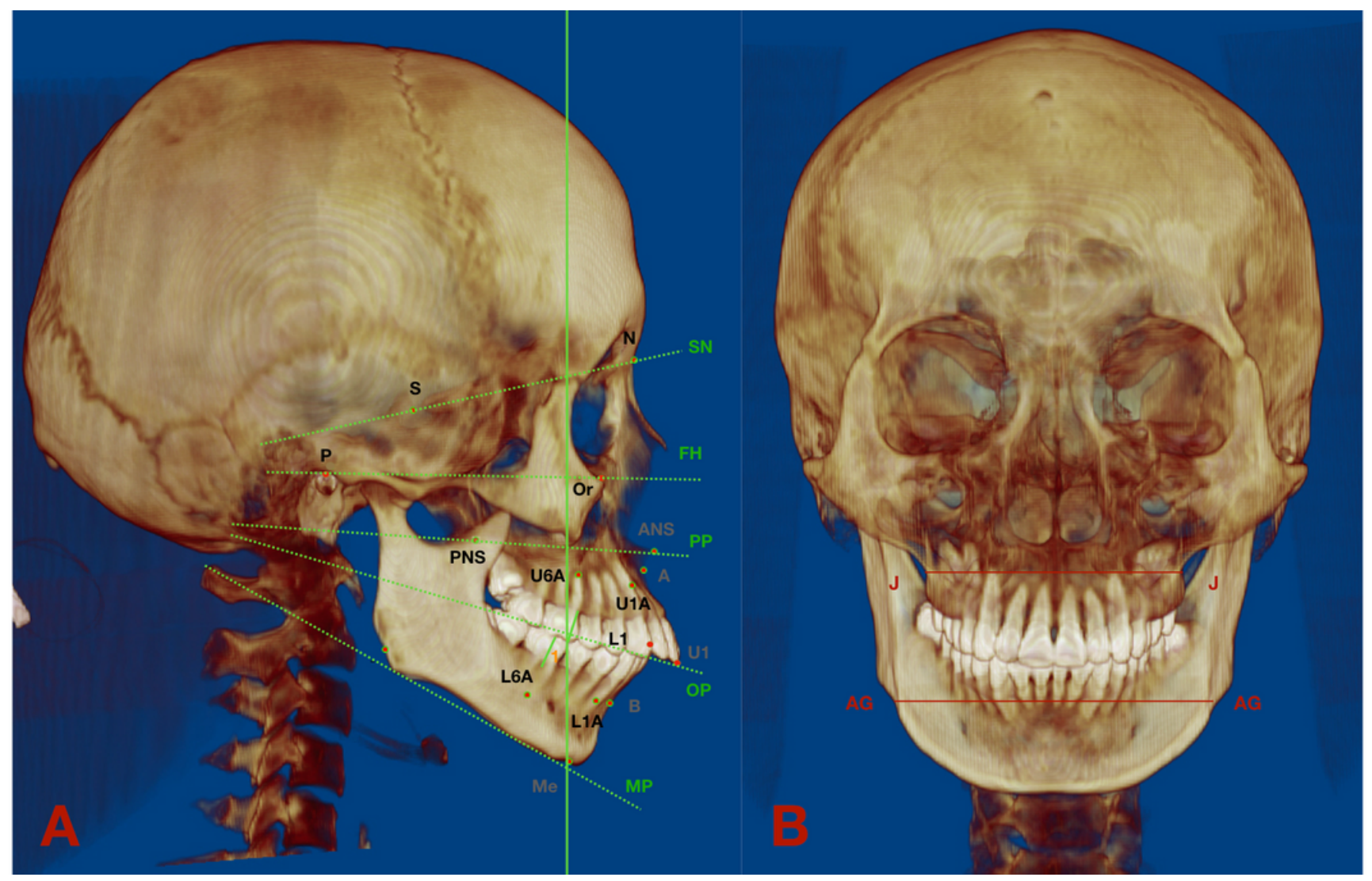

\section{Figure 4}

Landmarks, planes and measurements on the 3D reconstruction. A: the sagittal view: 1: 6-MD. B: the frontal view. 


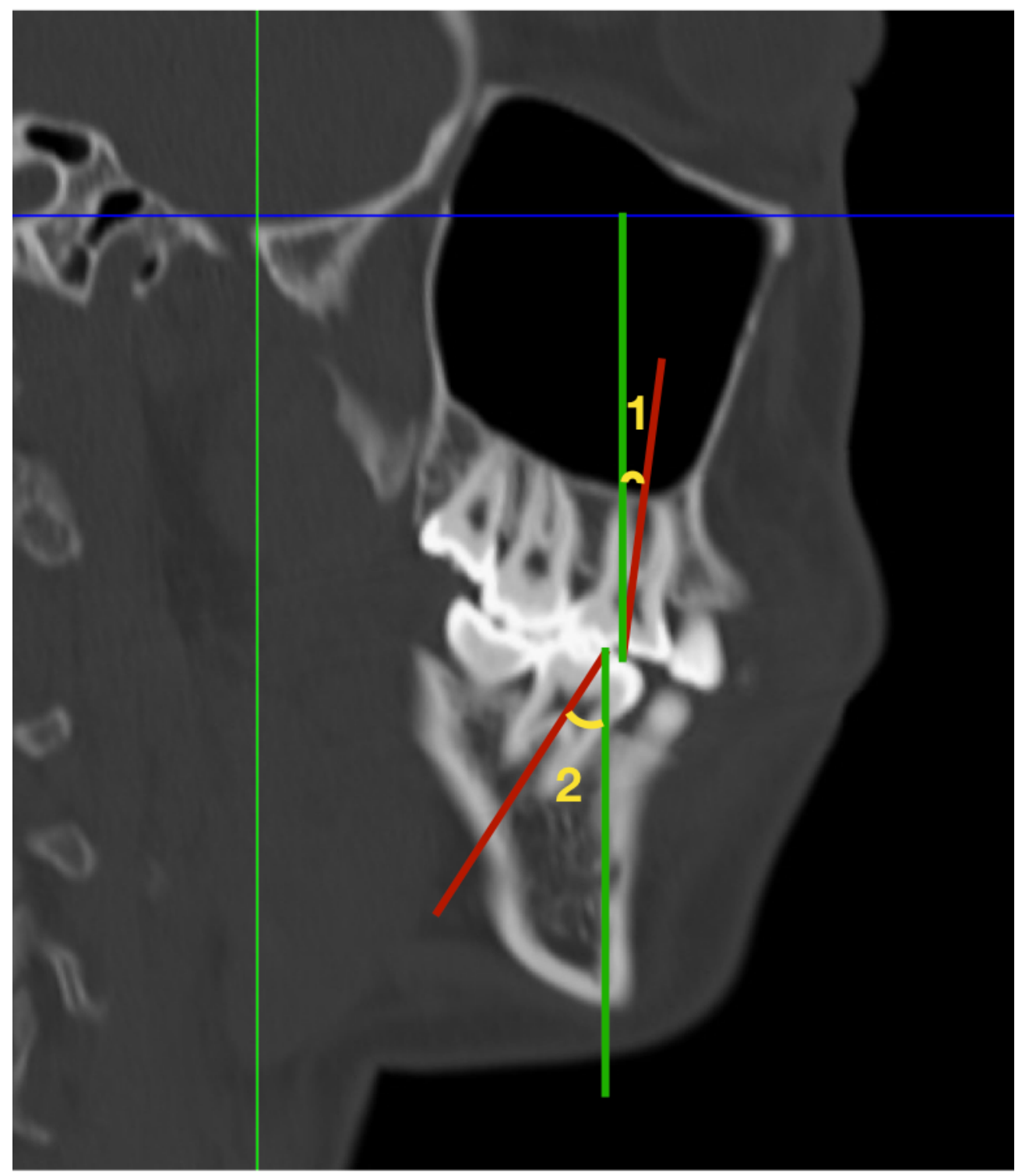

\section{Figure 5}

Angular measurements of right first molar on the sagittal CT image. Red line: the long axes of upper/lower first molar. Green line: planes parallel to the coronal plane. 1: R: $\angle \mathrm{U} 6 /$ Coronal; 2: R: L6/Coronal. 


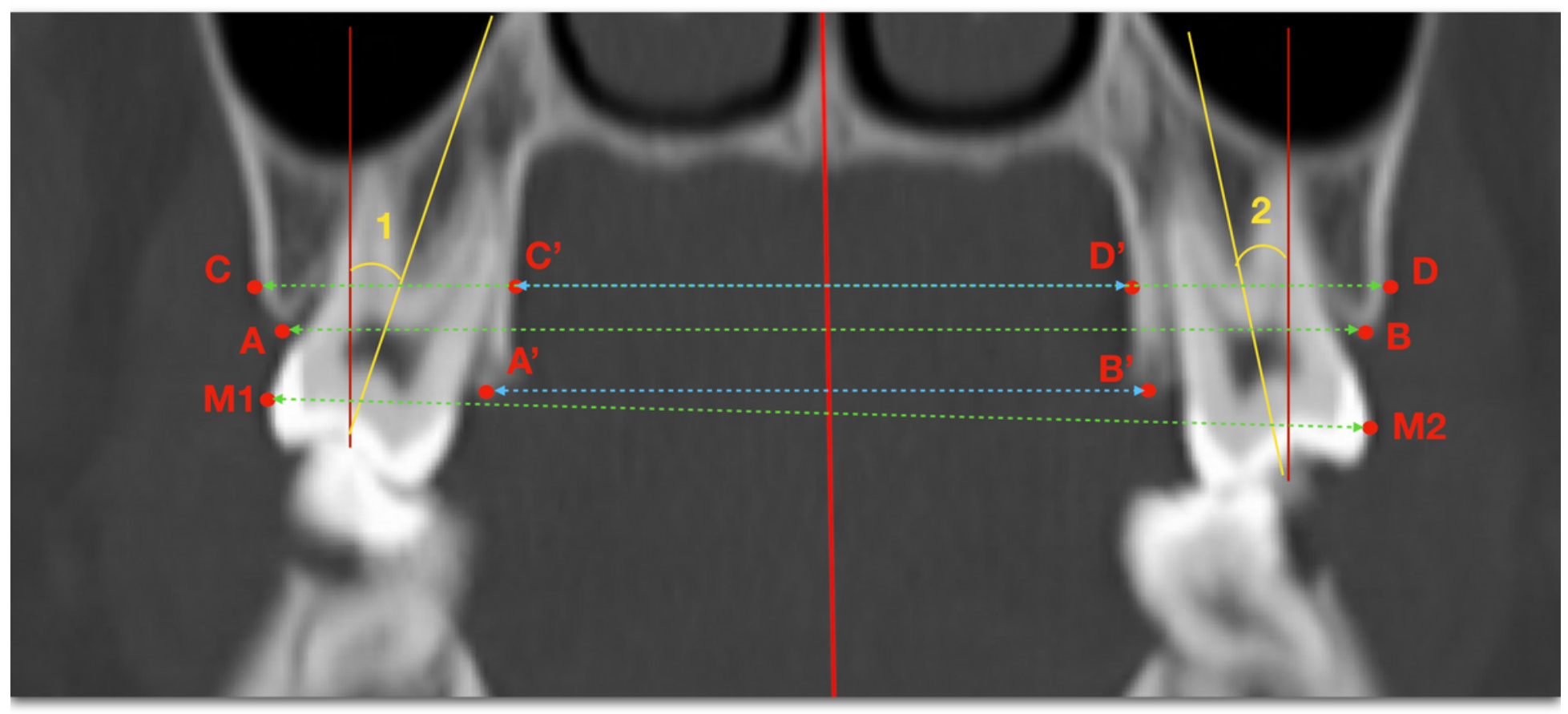

\section{Figure 6}

Linear and angular measurements of upper first molar on the coronal CT image. A-B: U6-AC; C-D: U6-MR; M1-M2: U6-IM; (AB$\left.A^{\prime} B^{\prime}\right) / 2$ : U6-BLW; (CD-C'D')/2: U6MR-BLW; 1: R: U6/Sagittal; 2: L: U6/Sagittal. 


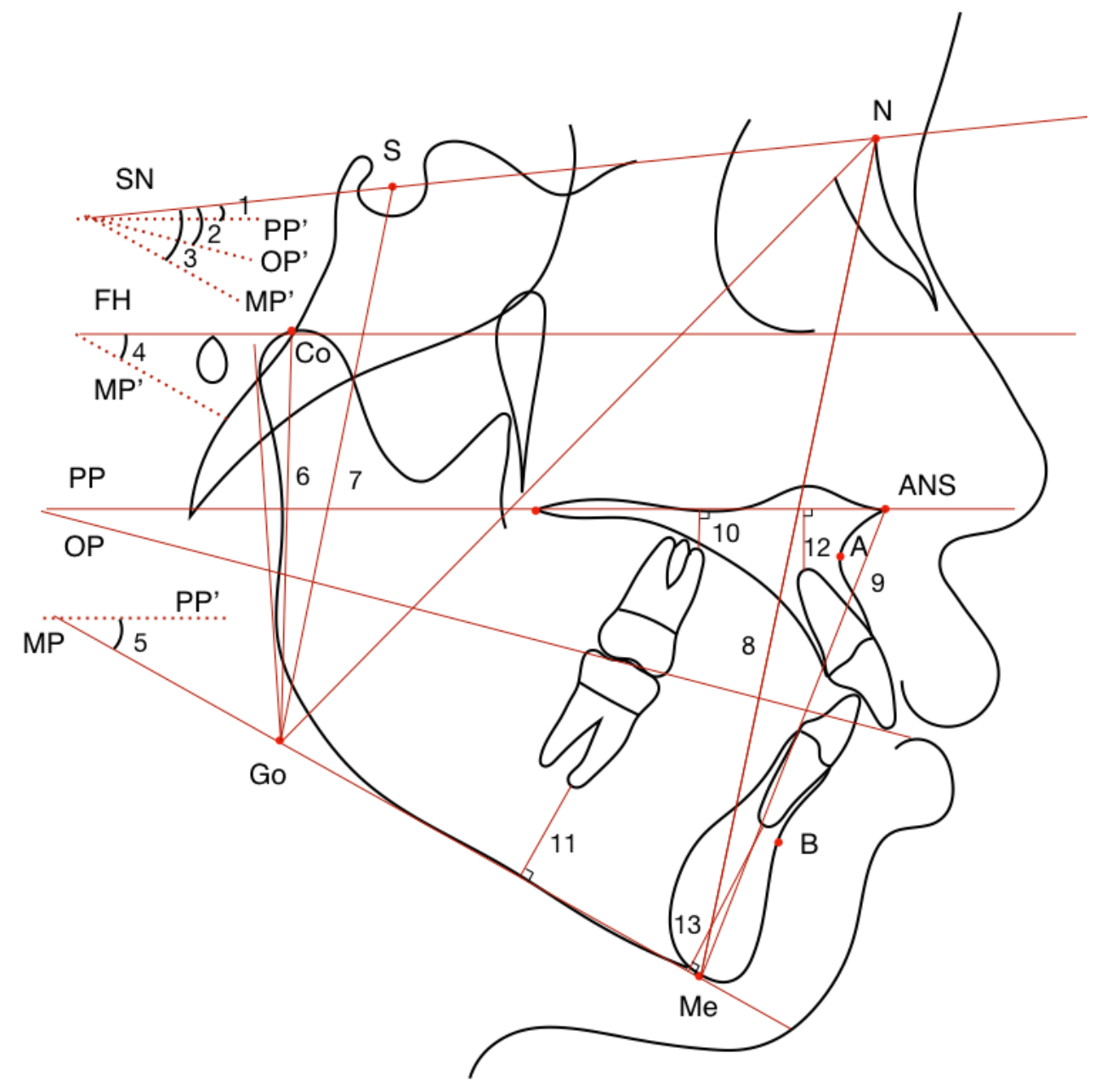

Figure 7

Parts of vertical variables. 1: $\angle \mathrm{SN}-\mathrm{PP} ; 2$ : $\angle \mathrm{SN}-\mathrm{OP}$; 3: $\angle \mathrm{SN}-\mathrm{MP} ; 4$ : $\angle \mathrm{FMA}$; 5: $\angle \mathrm{PP}-\mathrm{MP} ; 6$ : Co-Go; 7: S-Go; 8: N-Me; 9: ANS-Me; 10: U6-PP; 11: L6-MP; 12: U1-PP; 13: L1-MP. 


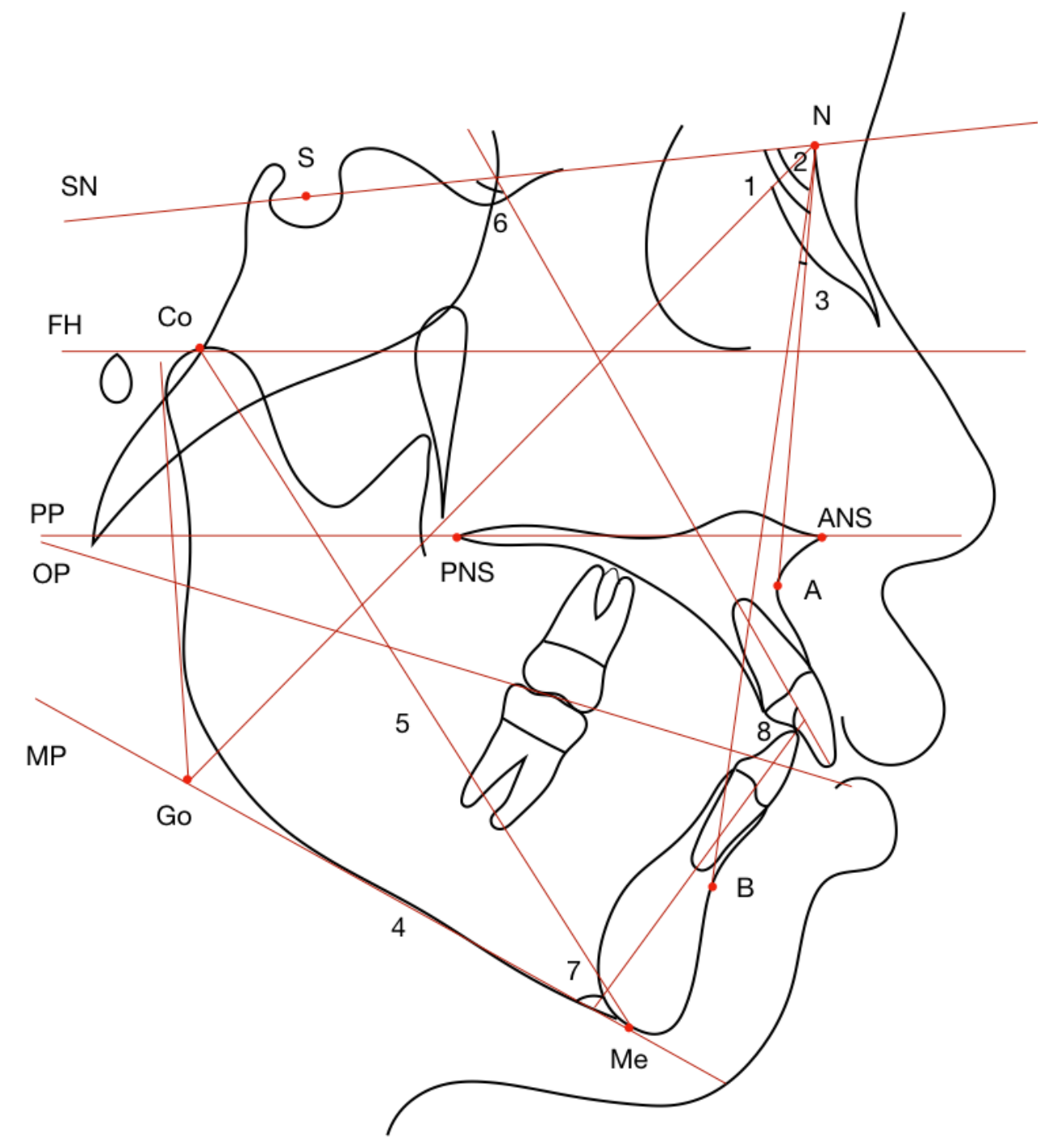

Figure 8

Parts of sagittal variables. 1: $\angle \mathrm{SNA} ; 2$ : $\angle \mathrm{SNB} ; 3: \angle \mathrm{ANB}$; 4: Go-Me; 5: Co-Me; 6: $\angle \mathrm{U} 1-\mathrm{SN} ; 7: \angle \mathrm{IMPA} ; 8: \angle \mathrm{U} 1-\mathrm{LI}$. 


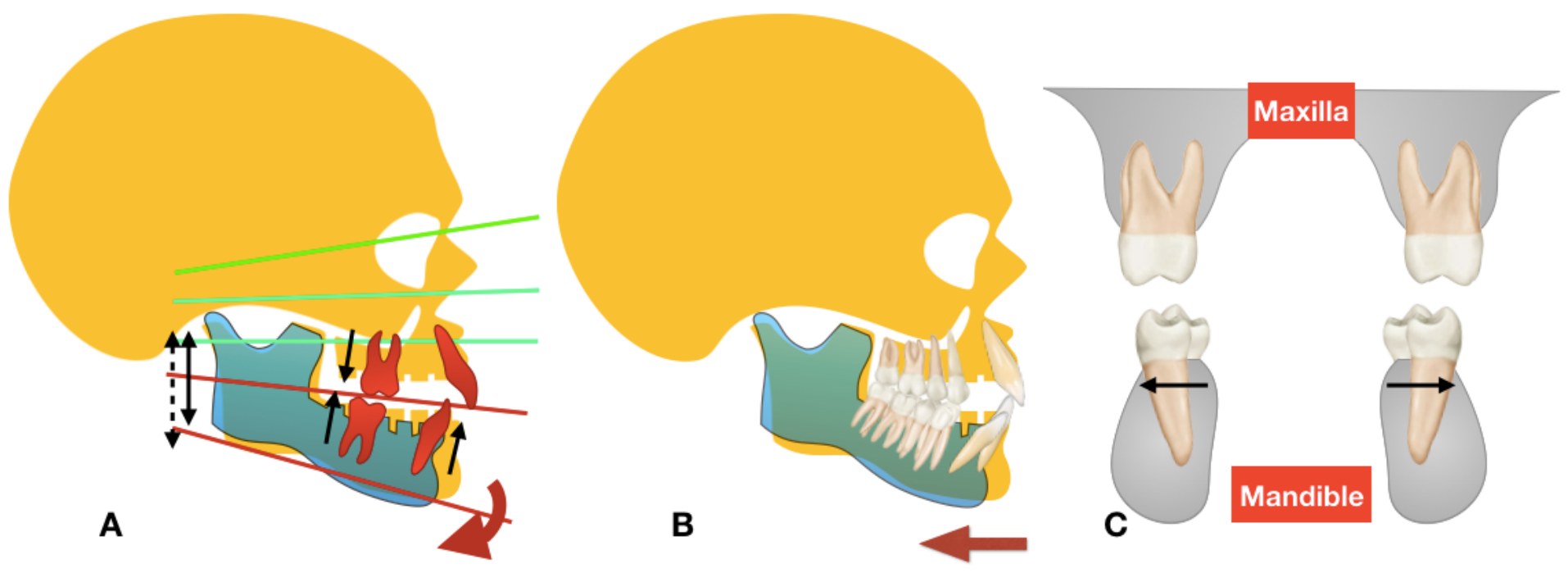

Figure 9

Schematic diagrams of dentoalveolar and skeletal characteristics as condylar volume decreased. 